\title{
A brief review on mechanical properties of Al-MMCs fabricated by stir casting route $\&$ applications
}

\author{
Abhishek Thakur, Ravinder Singh Joshi, Arshpreet Singh \\ Thapar Institute of Engineering and Technology, Patiala, India
}

\begin{abstract}
Aluminium metal matrix composites are pretty much important in the different demanding sectors such as in the field of medicine and engineering like automobiles, aerospace, defence, dental and consumer goods. The need arises due to its huge calibre in industrial need of good materials with lighter weight, excellent properties and economical in cost demanded the researchers or scientists research on composite materials. The AMMCs or Al-MMCs consists of an apex variety of mechanical properties which is directly proportional to the chemical composition of the Aluminium matrix. To enhance strength the reinforcement plays a key role in AMMCs could be in the form of continuous/ discontinuous fibres, whiskers \& particulate as the second phase depending on their applications and property requirements. In addition to it, various strength enhancers are reinforcements such as fly ash, $\mathrm{TiC}, \mathrm{SiC}, \mathrm{Al} 2 \mathrm{O} 3, \mathrm{TiO} 2, \mathrm{~B} 4 \mathrm{C}$ etc. This paper attempts to review the different combinations in the processing of aluminium metal matrix composites along with their properties and their applications.
\end{abstract}

\section{Introduction}

Aluminium based composites are nowadays the preferred choice due to their unique capacity of designing the materials to give required properties. Because of the quick development of modern industries and manufacturing systems the usage of aluminiumbased composites are expanding in different areas like aviation, marine, defence, automobile, on account of exclusive properties like higher strength to density ratio, higher stiffness to density ratio, better fatigue resistance, lower coefficient of thermal expansion, better wearresistance, better-elevated temperature properties. Matrix composites classified as:

- Metal matrix composites

- Organic matrix composites

- Polymer matrix composites

- Ceramics matrix composites [1].

The superior upgrade will be yielded in composites utilizing fibre supported materials towards their solidness and strength [2]. Fibre supported composites give the most elevated enhancements in strength and firmness [2]. Fibrous materials like whiskers are widely used these come under monocrystalline material. A monocrystalline material is made up of a single crystal throughout the body. Monocrystal material is difficult to form as they are costly and requires special condition. To form a monocrystalline material solidification starts at a single point $\&$ then grow by atoms leaving the liquid state and joining the solid-state like "whiskers". One of the research by G.sasaki et.al came to know that surface treatment of Al18B4O33 whisker can improve the hightemperature properties and good ageing behaviour [3].

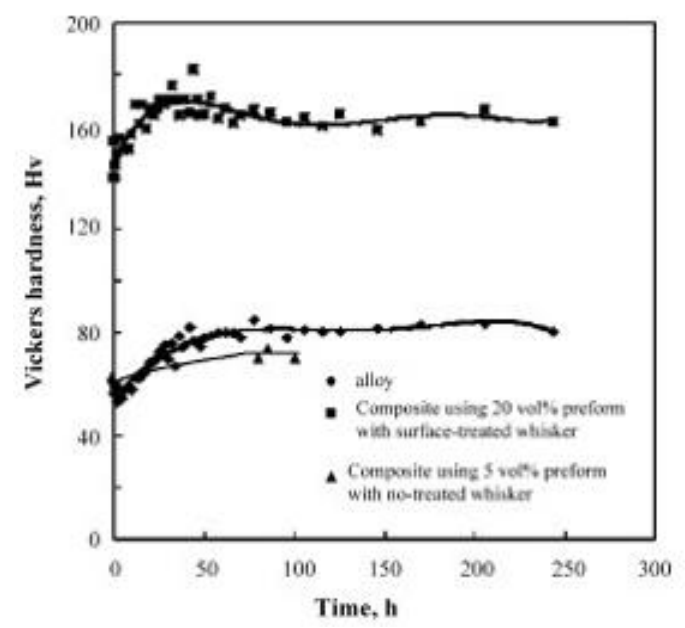

Fig.1 Age hardening behaviour whiskers vs time [3].

Whereas composites fabricated by the addition of reinforced particulates will pageant more isotropic behaviour and are efficiently fabricated by conventional techniques of metal processing. These metal matrix composites have a more auspicious nature in the modern material era instead of novel metal alloys. These MMCs are showing the most promising behaviour for the acceptance of the fast- growing industrial era and society challenges in sarcastic conditions [4].

\footnotetext{
* Corresponding author: author@e-mail.org
} 


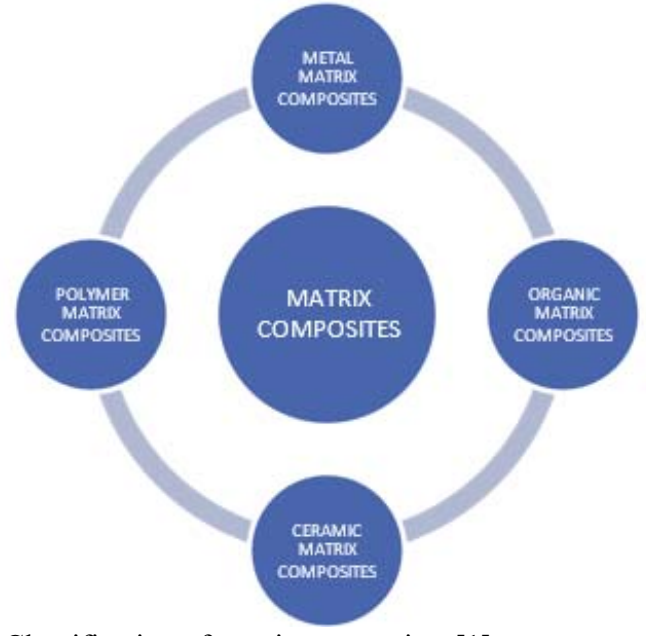

Fig.2 Classification of matrix composites [1].

\subsection{Composites}

Generation of exclusive and superior material by intermixing of two or more different materials. There is a tremendous enhancement in the usage of composites materials in recent time. Composites materials are used in tribology, electrical, thermal, and structural applications.

\subsection{Metal Matrix Composites (MMCs)}

Preparation of MMCs is made with base metal matrix and one or more discontinues phases. Fibres, whiskers and particles may be used as reinforcement substituent. Numerous benefits of metal matrix composites are high durability, high impact strength, and high modulus also against varying thermal conditions like variable temperature and shock MMCs show low sensitivity.

\subsection{Applications - from science to technology}

In the modern era, Metal matrix composites have a wide range of applications in auto, rail that is ground transportation, in aerospace, in industrial and in many more. As there is challenging demand for lightweight components in the automobile sector, an aerospace sector where the following demands of reinforcement for MMCs are generally applicable which is given below:-

- Low density

- Mechanical compatibility with thermal stability

- High young's modulus

- High compression and tensile strength

- Good processability

- $\quad$ Economic efficiency [5].

\subsubsection{Space Applications}

To reduce the weight of components in the aerospace industry an individual can make a huge saving in the fuel consumption either for an aeroplane or for the rocket because it carries a huge weight of fuel along with its weight that's why it is the need to reduce the weight by using the metal matrix composites. That is why the aeroplane and the rocket always try to replace all the metal parts with composites. So, that they can have a lightweight material to carry along with it which not even reduce the weight but also the fuel consumption and efficiency is drastically increased. Top rocket and exit of nozzle nowadays made up of composites. So, huge applications were found in the aerospace industry wherever metal matrix composites play a vital role [5].

\subsubsection{Automotive Applications}

Automobile Industry has a huge impact on the common man because they have improved fuel efficiency and they also enhance stiffness. So, the moment the stiffness enhances during an accident or crash these materials tries to yield and tries to transfer energy such that the passenger is slightly saved. Brake drums nowadays made up of MMCs earlier it was made up of cast iron. Wheel rim, titanium rims are coming up with Metal matrix composites. Brake discs (front and rear discs) are made up of Aluminium metal matrix composites all these discs are made up of aluminium alloys that are $\mathrm{AlSi} / \mathrm{Mg}$ which is reinforced with Sic [5].

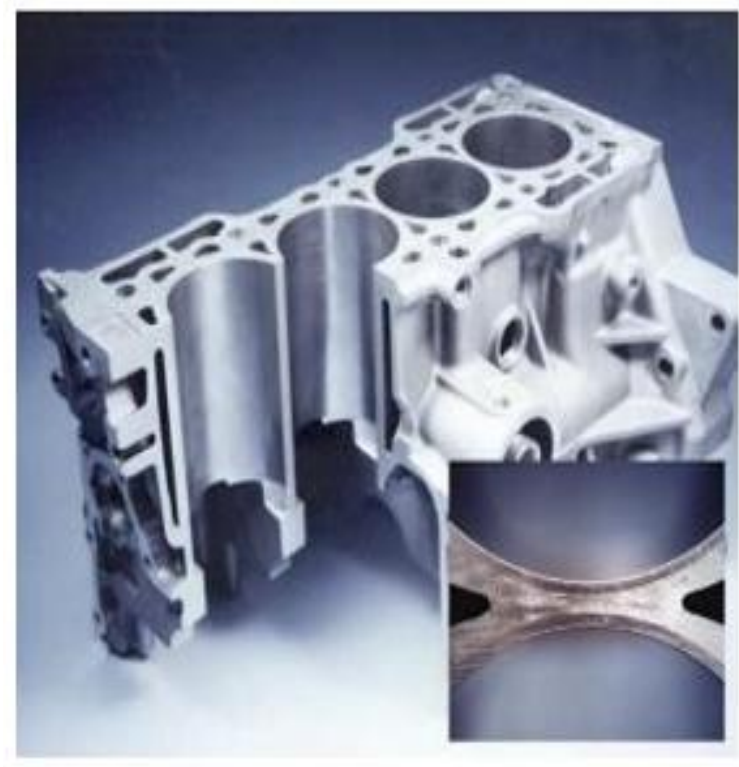

Fig.3 Representation of the engine block in bygone days it was made up of cast iron but now it is made with $\mathrm{Al} / \mathrm{Ti}$ mixed to form Metal matrix composites. Generally material used as: $\mathrm{AlSi}+$ Short fibres (whiskers) /or particulates [5].

\subsubsection{Power transmission applications Composite conductors.}

In the above figure, it is depicted that the number of small wires is tied inside and then they put a sleeve on top of it. These wires which installed are run for several kilometres. To avoid sagging support is necessarily applied at several points. Each supporting point is made out of a tower which includes high investment cost due to this MMCs comes into consideration or said to be an alternative to compensate with this issue. 
Initially, these cables are made out of conducting materials like copper, aluminium and other things. But with ongoing research, the scientists figured out the load on these wires that means to say the drawing power goes higher and higher and these materials have a tendency of sagging which is not required. To remove the sagging more and more towers are required which is again not economical.

So, by coming into existence of MMCs they could be made it of $\mathrm{Al} / \mathrm{Nextel}$ 610/45particulate then by using this density went down drastically which is $3.2 \mathrm{~g} / \mathrm{cm} 3$. The coefficient of thermal expansion (CTE) also went down drastically and the electrical conductivity is also enhanced by $34 \%$. And now the number of towers can be reduced by doing such applications and they have transmission power with lesser losses which is a big boon for the power transmission industry. The improvements by using MMCs gives tremendous improvement for the power transmission industry which is given below:-

- Electrical conductors material: MMC-

$\mathrm{Al} / \mathrm{Nextel610/45 \textrm {F }}$

- Tensile strength : $1200 \mathrm{MPa}$

- Density : $3.2 \mathrm{~g} / \mathrm{cm} 3$

- Coefficient of thermal expansion (CTE): $6.6 \mathrm{ppm} / \mathrm{k}$

- Electrical conductivity : $34 \%$ [5].

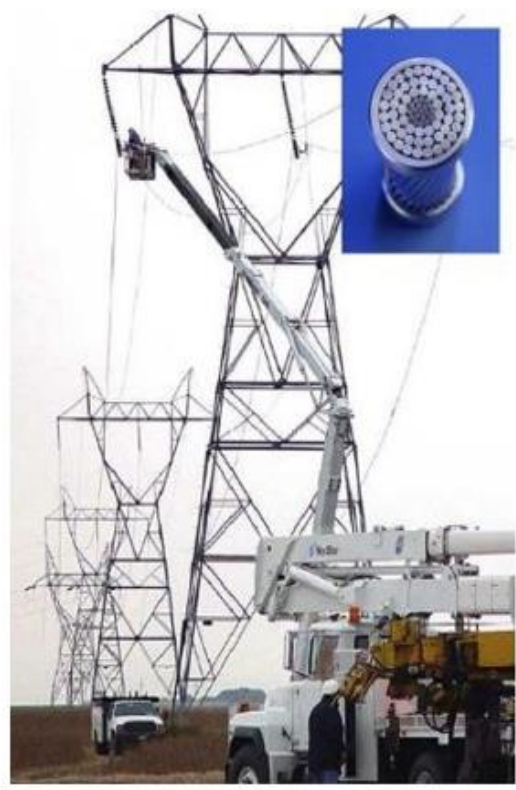

Fig.4 Representation of power transmission towers with MMCs conductor cable installed with it [5].

\subsection{Fabrication of metal matrix composites}

As within few recent years, there is a tremendous rise in the application of AMCs. AMCs have much more advancement than monolithic metals. Various processing techniques of AMCs have detailed here Classification of These processes is based on metal matrix temperature. The characterizations of different techniques are as follows. Liquid phase process, Solid Liquid phase process, Deposition process, In situ process[6].

\subsection{Classification of Metal matrix composites based on reinforcement}

In particles based reinforced MMCs, there is a small particle with less aspect ratio that is $\mathrm{L} / \mathrm{d}$ ratio. It may be $1,2,3,4$ but must be less than 5 . So, the moment $\mathrm{L} / \mathrm{d}$ ratio less than 5 leads to very small particles dispersed in the matrix. To be a slightly higher ratio of $\mathrm{L} / \mathrm{d}$ then leads to the use of short fibres or whiskers. These fibres are generally made up of glass or ceramics. From figure. 6 , In these three cases the metal will be taken into a liquid state and then brought to a solid-state then can be started with the solid sheet and then keep the reinforcement sandwiched in between together to get the composites. Continuous fibres or sheet reinforced MMCs are generally used for high strength applications.

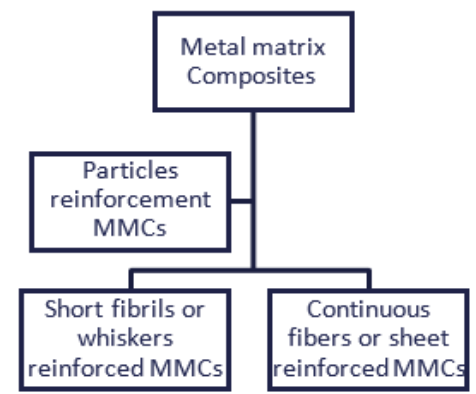

Fig.5 Hierarchy chart of MMCs based on reinforcement [7]

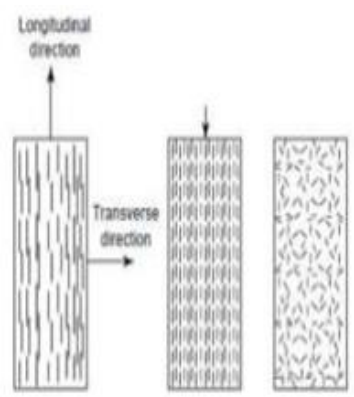

Fig.6 Representation of (a) Continuous and aligned fibre composites (b) Discontinuous and aligned fibre composites (c) Discontinuous and randomly oriented composites [7]

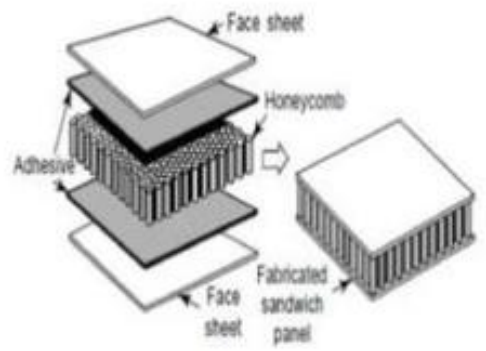

Fig.7 Representation of sandwiched reinforced MMCs [7]

\section{Processing of metal matrix composites}

-Metal matrix composite materials can be produced by many different techniques. 
-The focus of the selection of suitable process engineering is the desired kind, quantity and distribution of the reinforcement components (particles and fibres), the matrix alloy and the application.

-By altering the manufacturing method, the processing and finishing as well as by the form of the reinforcement components it is possible to obtain different characteristic profiles, although the same composite and amounts of the components are involved. So, by just playing with the process parameters an individual can even try to change the mechanical properties of an individual requirement.

\subsection{Liquid Phase Process}

It involves the integration of the dispersed phase with that of molten matrix metal followed by solidification[8]. To provide minimum reaction between the dispersed phase and molten matrix metal ensure that surfaces of the above two must be properly cleaned before mechanical stirring[9].

\subsubsection{Stir Casting Fabrication Technique}

In recent years there is a massive rise in the development of Al-based MMCs commercially via the stir casting route due to their integrity, flaccidity and costeffectiveness. It is also alluring for large- scaled and complex components production due to its conventionalism. It implicates intermixing of reinforcement with that of molten metal through continuous mechanical stirring at a suitable speed of the electric motor followed by solidification. Reinforcement must be pre-treated through the required technique to remove the moisture content which leads to poor wettability[10]. The stir casting fabrication process technique is shown in the figure. 9

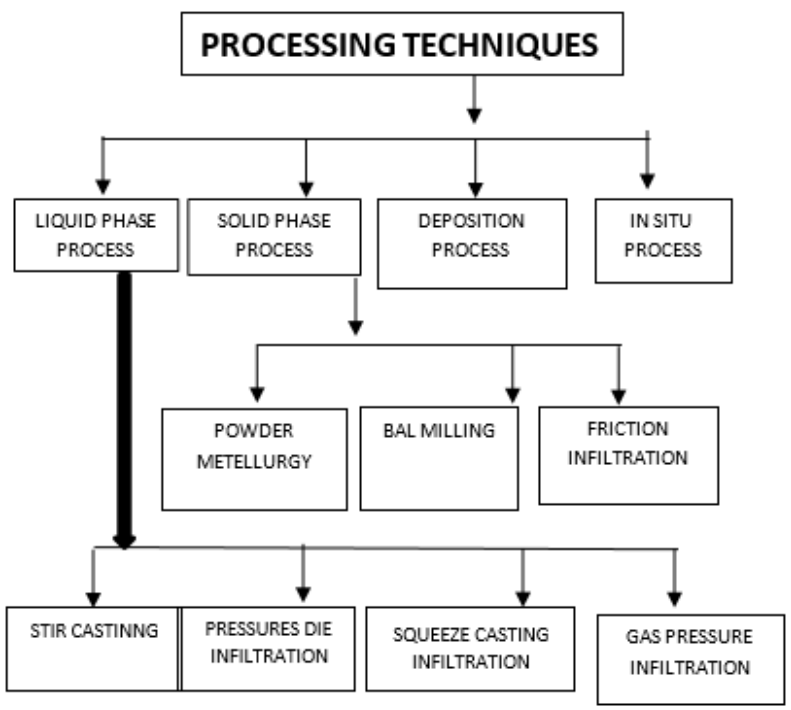

Fig. 8 Classification of distinct Fabrication Techniques.

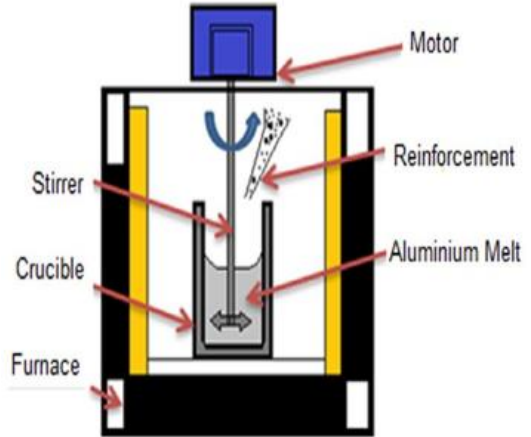

Fig.9 Stir Casting Apparatus [11].

\subsubsection{Process variables of stir casting fabrication technique}

There is a huge demand for composites materials than monolithic alloy in the rapidly growing industrial urbanization. Stir casting technique for fabricating Albase metal matrix composites are the most convincing and authentic way under the Liquid metallurgy fabrication technique due to its larger-scale production and economic factors. So numerous factors must be taken into consideration for effective manufacturing of MMCs like 1) wettability among base metal alloy and reinforced material 2) porosity 3) homogenous dissemination of reinforced material. 4) Chemical reception among base metal alloy and reinforced materials [11].

\section{Characterization of mechanical properties}

It refers to the examination of mechanical properties which caters for the basis for restraining the deterioration of the materials during its deployment in various fields. Elastic, toughness and fracture are the basic strength pertinent properties of mechanical testing. There is an immense effect of wettability among base metal matrix and reinforced particulates on mechanical properties.

Optical micrographs will be used for evaluating the distribution of reinforced particulates in composites[9]. For analysis of these prerequisite properties, different specimens were fabricated according to the ASTM standards for testing[7]. Specimens were machined before testing. Also, polished and flat surfaces of the specimens were obligatory for microstructural analysis. Hardness tests were conducted on any of the following machine, the Brinell hardness testing machine, Vickers's hardness testing machine[11].

\subsection{Literature Review}

H.Abdizadeh et al. conducted a study on the mechanical behaviour of $\mathrm{Al} 356$ based nano $\mathrm{MgO}$ reinforced composites fabricated by stir casting technique. They carried out a metal casting operation at $900 \mathrm{C}$ under a stirring speed of $420 \mathrm{rpm}$ for 14 minutes. They revealed that in comparison to monolithic alloy there is a gain in 
hardness and compressive strength on the addition of $\mathrm{MgO}$ nanoparticles as reinforcement in a base metal matrix. Also, they convicted that for the superior enrichment of mechanical properties the optimal handling temperatures of melt must be $850 \mathrm{C}$ [12].

K. Amouri et al. studied the mechanical properties of Al356-nano/micro SiC MMCs fabricated by the stir casting method. In their experimentation, they used A1356 alloy as base metal matrix and $\mathrm{SiC}$ as reinforcement of nano and micro sizes. A conventional metal forming process was carried out at $800 \mathrm{C}$ under a mechanical stirring action of $600 \mathrm{rpm}$ for 7 minutes. Then they affirmed that there is a rise in both tensile and compressive strength with the admittance of nano/micro reinforced particles. Also, it was comprehended that tensile and compressive strength was maximum at $1.5 \mathrm{wt}$. $\%$ of nano $\mathrm{SiC}$ as reinforcement. Low ductility was observed in the tested samples mainly due to the brittle behaviour of Sic. so overall there is a remarkable rise in mechanical properties of $\mathrm{Al}$-nano/micro SiC MMCs on the liability of ductility as compared to novel Al356 alloy [13].

A.Baradeswaran and Elaya Perumal investigated the mechanical characteristics of Al 7075- graphite MMCs manufactured by stir casting technique. In their analyses, the base matrix of Al-70075 alloy and graphite as a reinforcement of varying size between $20 \mu \mathrm{m}$ to $26 \mu \mathrm{m}$ was used. Using stir casting fabrication technique specimens were processed at $800 \mathrm{C}$ temperature of the melt stirred at $500 \mathrm{rpm}$ for 5 minutes. In a similar fashion different specimens were prepared using $5,10,15,20 \mathrm{~W} \%$ of graphite. Then hardness test was conducted on these prepared samples. It was concluded by them that there is decreasing trend in hardness was observed with the rise in inclusion of graphite $\mathrm{W} \%$ in a base matrix [14].

Bharath V et al. synthesized A16061-A12O3 MMCs by conventional metal casting method for interpretation of mechanical properties. For the current study, Al6061 is used as base metal matrix and $\mathrm{Al} 2 \mathrm{O} 3$ particles as reinforcement of size $125 \mu \mathrm{m}$. For the experimental analyses, composites are processed at 6, 9, and $12 \mathrm{~W} \%$ variant proportion of $\mathrm{Al} 2 \mathrm{O} 3$ particles. The maximum temperature of melt was $8000 \mathrm{C}$. Conventional metal forming technique was used for fabrication of composites using mechanical stirrer for uniform mixing of reinforced particles. Substitution of $\mathrm{Al} 2 \mathrm{O} 3$ particles was carried out in a three-stage process under mechanical agitation of 200rpm for 10 minutes in every stage [15].

S.Chaudhury et al. formulated the mechanical behaviour of Al-2Mg- Ti02composites fabricated by stir casting method. For the current study, they use Al- Mg as base metal matrix and Ti02 as reinforcement. The temperature of the melt was $400 \mathrm{C}$ and experimented with the mechanical agitation of $300 \mathrm{rpm}$ for 8minutes.hot and cold rolling were processed out for the amalgamation of composites and alloy. Then they revealed that there is an enhancement in ultimate tensile strength [16].

U Ramakant et al. studied the mechanical properties of the Al-Zn alloy based hybrid MMC using SiC and fly ash as reinforcement by conventional metal casting technique. For the current study, they used Al-Zn (A7075) alloy as base metal matrix and $\mathrm{SiC}$ along with fly ash particulates as reinforcement for the preparation of hybrid composite. Numerous fractions with an average particulate size of $53 \mu \mathrm{m}$ of $\mathrm{SiC}$ and fly ash were used varying from $(0-15 \%)$ by weight for the fabrication of different samples as shown in table no 1 . The melt is prepared by using a muffle furnace stirred under the mechanical agitation of $450 \mathrm{rpm}$ for the homogenous flow of particles reinforced. Then they affirmed that there is an escalation in the hardness value of the hybrid composite using $\mathrm{SiC}$ and fly ash particulates as reinforcement then base metal alloy. Also, they admitted that with the rise in the proportion of $\mathrm{SiC}$ and fly ash as reinforcement the ultimate tensile strength and yield strength increases as compared to the nascent metal alloy [17]. Graphical interpretation of the tensile nature is shown in fig. 10.

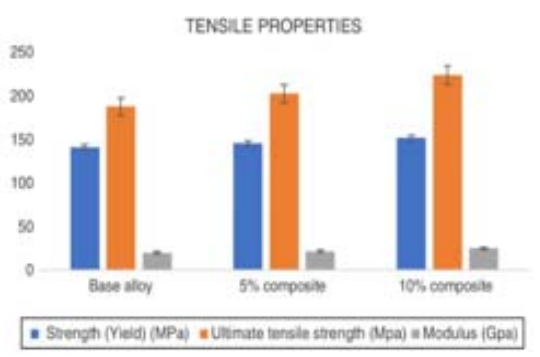

Fig. 10 Histogram showing tensile behaviour with variate wt. fractions of reinforcement [17]

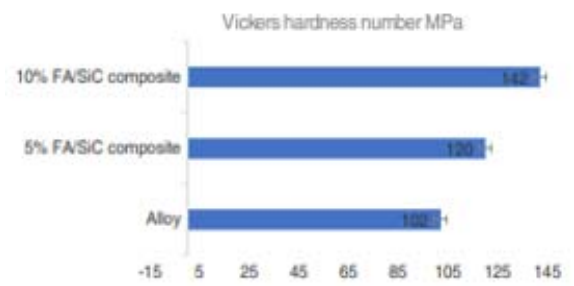

Fig. 11 Representation of the enhancement in the hardness w.r.t. reinforcement content [17].

M. Krishnaa and A. Xaviorb synthesized $\mathrm{SiC}$ and graphite-reinforced Al6061 based hybrid MMC for the analysis of mechanical behaviour using metal casting technique. For the present study, they had used aluminium as base matrix and $\mathrm{SiC}$ along with graphite as reinforcement for the preparation of hybrid composite. For improving the wettability $\mathrm{Mg}$ was added before the inclusion of reinforcement. The temperature of the melt was nearby $760 \mathrm{C}$. The stirrer was stationed up to $2 / 3 \mathrm{rd}$ of the elevation of the smelted metal from the basement and stirred at $200 \mathrm{rpm}-400 \mathrm{rpm}$ for $10-20 \mathrm{~min}$ duration. Then they revealed that there is improvement in the mechanical response of the processed hybrid composite. With the rise in wt fraction of $\mathrm{SiC}$ and graphitereinforced particulates, there is a remarkable 
enhancement in the tensile strength as shown in fig. 12 and for density observation, following the reinforcements, there is a significant change in the density according to the wt. percentage as shown in fig.13 given below. Also, they convicted that there is superior enrichment in the tensile strength of hybrid composite as compared to $\mathrm{SiC}$ as single reinforcement in Al6061 base metal [18].

\begin{tabular}{|c|c|c|c|c|}
\hline \multicolumn{5}{|c|}{ Table. 1 [17] } \\
$\begin{array}{c}\text { Sr. } \\
\text { No }\end{array}$ & $\begin{array}{c}\text { Sample } \\
\text { Number. }\end{array}$ & Composition & $\begin{array}{c}\text { SiC } \\
\text { weight\% }\end{array}$ & $\begin{array}{c}\text { fly ash } \\
\text { weight\% }\end{array}$ \\
\hline 1. & Sample no 1 & $\mathrm{A} 7075$ & 0 & 0 \\
\hline 2. & Sample no 1 & $\begin{array}{c}\mathrm{A} 7075+2.5 \% \\
\mathrm{SiC}+ \\
2.5 \% \text { fly-ash }\end{array}$ & 2.5 & 2.5 \\
\hline 3. & Sample no 1 & $\begin{array}{c}\mathrm{A} 7075+5 \% \mathrm{SiC} \\
+ \\
5 \% \mathrm{Fly}-\mathrm{ash}\end{array}$ & 5 & 5 \\
\hline
\end{tabular}

\section{Results and Discussions:}

\subsection{Tensile test:}

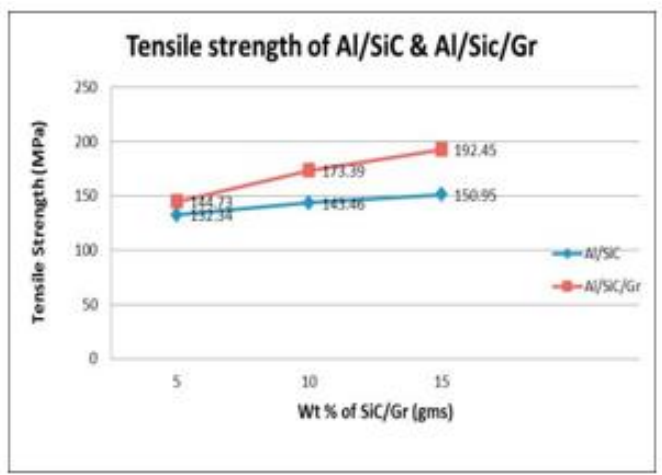

Fig. 12 Representation Tensile Strength in accordance with reinforcement [18].

\subsection{Density test:}

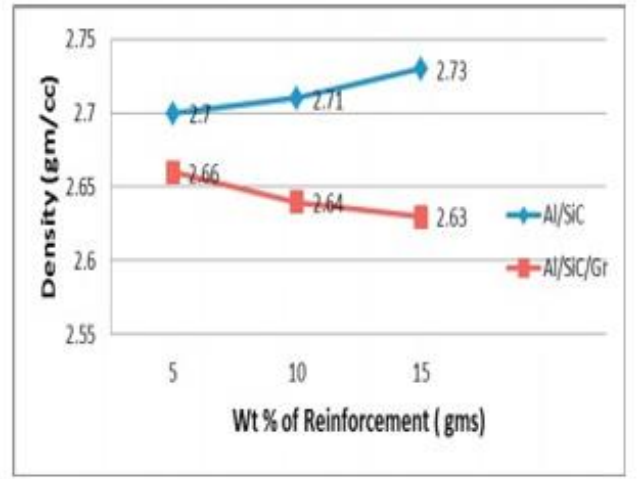

Fig. 13 Representation of variation of densities in accordance with reinforcement [18].

From figure 12 it is depicted that the tensile strength of composites drastically increased due to the addition of wt. percentage of reinforcement. In the case of $\mathrm{Al} / \mathrm{SiC} / \mathrm{Gr}$ that is in hybrid composites gains more tensile strength as compared to single reinforcement $(\mathrm{Al} / \mathrm{SiC})$ addition. Similarly, from the figure 13 it is depicted that the density variation is there that is for single reinforcement the density is more as compared to a hybrid one.

\section{Conclusion}

-It has been noticed that the weight fractions or percentage majorly influenced the mechanical properties of the composites such as tensile strength, density etc.

-From a research point of view, it reveals that the reinforcement generally uniforms distributed in the matrix.

-Mechanical compatibility, good processability and economic efficiency enhanced by using MMCs.

\section{References}

[1] Ramnath, B. V., Elanchezhian, C., Annamalai, R. M., Aravind, S., Atreya, T. S. A., Vignesh, V., Subramanian, C., Rev. Adv. Mater. Sci, 38, 55 (2014).

[2] Manoharan, M., Lewandowski, J. J., Scripta metallurgical, 23, 1801 (1989).

[3] Sasaki, G., Wang, W. G., Hasegawa, Y., Choi, Y. B., Fuyama, N., Matsugi, K., Yanagisawa, O. Journal of materials processing technology, 187, 429 (2007)

[4] Doddamani, S., Kaleemulla, M., Fratturaed Integrità Strutturale, 11,484 (2017).

[5] Miracle, D. B., Composites science and technology, 65, 2526 (2005).

[6] Kandpal, B. C., Singh, H., Materials Today: Proceedings, 4, 2783 (2017).

[7] Idrisi, A. H., Deva, S., International Journal of Engineering Research and Technology, 3, 1303 (2014).

[8] Kandpal, B. C., Kumar, J., Singh, H., Materials Today: Proceedings, 5, 5 (2018).

[9] Sijo, M. T., Jayadevan, K. R., Procedia Technology, 24, 379 (2016).

[10] Kumar, S. M., Pramod, R., Govindaraju, H. K., Materials Today: Proceedings, 4, 509 (2017).

[11] Sharma, V. K., Singh, R. C., Chaudhary, R., Engineering science and technology, an international journal, 20, 1318 (2017).

[12] Abdizadeh, H., Ebrahimifard, R., Baghchesara, M. A., Composites Part B: Engineering, 56, 217 (2014).

[13] Amouri, K., Kazemi, S., Momeni, A., Kazazi, M., Materials Science and Engineering: A, 674, 569 (2016).

[14] Baradeswaran, A., Perumal, A. E., Composites Part B: Engineering, 56, 472 (2014).

[15] Bharath, V., Nagaral, M., Auradi, V., Kori, S. A.,Procedia materials science, 6, 1658 (2014).

[16] Chaudhury, S. K., Singh, A. K., Sivaramakrishnan, C. S., Panigrahi, S. C., Materials Science and Engineering: A, 374, 184 (2004).

[17] Kanth, U. R., Rao, P. S., Krishna, M. G., Journal of Materials Research and Technology, 8, 737 (2019). 